\section{Editorial}

Check for updates

\section{OPEN ACCESS}

Received: Nov 28, 2019

Accepted: Dec 1, 2019

Address for Correspondence:

Byung Joo Sun, MD, PhD

Division of Cardiology, Department of Internal

Medicine, Chungnam National University

Hospital, Chungnam National University

School of Medicine, 282 Munhwa-ro, Jung-gu,

Daejeon 35015, Korea.

E-mail: bjcardio@hanmail.net

Copyright (c) 2020 Korean Society of

Echocardiography

This is an Open Access article distributed under the terms of the Creative Commons Attribution Non-Commercial License (https:// creativecommons.org/licenses/by-nc/4.0/) which permits unrestricted non-commercial use, distribution, and reproduction in any medium, provided the original work is properly cited.

\section{ORCID iDs}

Byung Joo Sun (iD

https://orcid.org/0000-0001-6019-4343

\section{Conflict of Interest}

The authors have no financial conflicts of interest.

\title{
Right Ventricle and Acute Preload Change
}

\section{Byung Joo Sun (1D, MD, PhD}

Division of Cardiology, Department of Internal Medicine, Chungnam National University Hospital, Chungnam National University School of Medicine, Daejeon, Korea

- See the article "Right Ventricular Analysis Using Real-time Three-dimensional Echocardiography for Preload Dependency" in volume 28 on page 36.

For a long-time, most cardiologists have mainly focused on the left ventricle, coronary artery, and the systemic arterial perfusion. Usually, clinicians do not put a priority on the right ventricle (RV) in practice because most disease entities in the RV present with gradual progression. Moreover, conventional 2-dimensional (2D) echocardiography has substantial limitations for quantification of the RV. ${ }^{1)}$ Recently, however, many cardiologist groups are focused on pulmonary hypertension and tricuspid regurgitation, and accordingly are focusing their attention on the RV. Now the RV is no more 'a forgotten chamber', but a new field of opportunity for many cardiology researchers. Interestingly, the unique function of the $\mathrm{RV}$ - connecting the systemic venous flow to the pulmonary vascular bed - has motivated development of research topics which investigate the RV and associated systemic diseases. ${ }^{2)}$

In this issue of the Journal of Cardiovascular Imaging, Kwon et al. ${ }^{3)}$ contributed a research article in which they report results of sequential echocardiography in 58 patients with maintenance hemodialysis (HD) immediately before and after the HD. Through analysis of 3-dimensional (3D) full volume images focused on the RV, they report that 3D-derived RV volume and stroke volume were significantly decreased after HD. The RV ejection fraction and strain were also reduced.

This research article has two focuses. First, the authors demonstrated significant RV geometric and functional changes after HD. This finding provided evidence that the physiological concept that the RV is a preload-dependent chamber in a special clinical situation with HD is accurate. Accordingly, echocardiography was shown as a feasible tool to evaluate relevant RV changes. Second, the authors described the compatibility of 3D echocardiography for evaluation of the RV. Actually, they hypothesized that 3D imaging is superior to the conventional 2D method for evaluation of the 'crescent-shaped RV'. In this regard, they reported there is a significant difference in all $\mathrm{RV}$ parameters when comparing 3D and 2D images, therefore they hypothesized that the 3D parameters would be closer to ground truth. But, one critical gap should be pointed out. That is, the present study lacked a reference modality (e.g., cardiac magnetic resonance imaging [CMR]). Therefore, the current study results cannot be accepted as a robust evidence of the superiority of 3D imaging for RV evaluation. It would be reasonable to suggest that the authors' conclusion was only based on comparison with the previous research regarding 3D RV images. ${ }^{45)}$ 
Nevertheless, the real value of this research is that the authors had an excellent insight into the HD patient group as a real clinical model of acute preload reduction, and they performed sequential echocardiographic evaluations just before and after HD (probably with several obstacles in a clinical situation). Hopefully, there will be many following studies based on this pilot work. For example, inter-modality validation in a clinical situation with a reference gold standard (such as CMR) should be undertaken. The clinical impact of RV adaptation to acute preload changes also needs to be studied in the future.

\section{REFERENCES}

1. Rudski LG, Lai WW, Afilalo J, et al. Guidelines for the echocardiographic assessment of the right heart in adults: a report from the American Society of Echocardiography endorsed by the European Association of Echocardiography, a registered branch of the European Society of Cardiology, and the Canadian Society of Echocardiography. J Am Soc Echocardiogr 2010;23:685-713. PUBMED | CROSSREF

2. Vonk Noordegraaf A, Westerhof BE, Westerhof N. The relationship between the right ventricle and its load in pulmonary hypertension. J Am Coll Cardiol 2017;69:236-43. PUBMED | CROSSREF

3. Kwon A, Ahn HS, Kim GH, Cho JS, Park CS, Youn HJ. Right ventricular analysis using real-time threedimensional echocardiography for the dependency of preload. J Cardiovasc Imaging 2020;28:36-47. PUBMED | CROSSREF

4. Medvedofsky D, Maffessanti F, Weinert L, et al. 2D and 3D echocardiography-derived indices of left ventricular function and shape: relationship with mortality. JACC Cardiovasc Imaging 2018;11:1569-79. PUBMED | CROSSREF

5. Kjaergaard J, Petersen CL, Kjaer A, Schaadt BK, Oh JK, Hassager C. Evaluation of right ventricular volume and function by 2D and 3D echocardiography compared to MRI. Eur J Echocardiogr 2006;7:430-8. PUBMED | CROSSREF 